\title{
La lucha contra el cierre de Altos Hornos del Mediterráneo de Sagunto (Valencia)
}

\author{
ENRIQUe GonZÁLEZ DE ANDRÉS \\ Alumno de Doctorado UNED
}

\section{The fight against closure of Altos Hornos del Mediterraneo in Sagunto (Valencia)}

La lucha de los trabajadores de Altos Hornos del Mediterráneo (AHM) de Sagunto (Valencia) contra el cierre de la cabecera entre los años 1983 y 1984 constituyó un hito en toda regla. El Gobierno del PSOE propuso una reconversión industrial en la que los principales afectados serían los

trabajadores del sector. Las formas de organización con que se dotó el pueblo de Sagunto inmediatamente posibilitaron que la participación fuera muy amplia y extensa, lo que presionó, a su vez, a los directivos de la siderurgia, al Gobierno, a los sindicatos y a los partidos de izquierda, siendo una constante a lo largo de todo el conflicto. Las innumerables huelgas, concentraciones, marchas a Valencia y a la capital de España mostraron la enorme disposición de la clase trabajadora por defender los puestos de trabajo. Sin embargo, aquella demostración no echó atrás los planes previstos.

PALABRAS CLAVE:

siderurgia, Altos Hornos del Mediterráneo, clase trabajadora, sindicatos de clase, PSOE, reconversión industrial.

\begin{abstract}
The struggle of workers in the Altos Hornos del Mediterráneo (AHM) Sagunto (Valencia) against the closure of the head between 1983 and 1984 was a landmark in the whole rule. The PSOE Government's proposed industrial restructuring in which the main victims were workers. The town of Sagunto took such organization measures that people participation was very broad and extensive, and, consequently, management of iron and steel industry, government, trade unions and left-wing political parties were pressurized. It was a constant throughout the conflict. The numerous strikes, rallies and marches to Valencia and the Spanish capital showed the enormous willingness of the working class to defend jobs. However, that demonstration didn't stop the plans.
\end{abstract}

\section{KEYWORDS:}

iron and steel industry, Altos Hornos del Mediterráneo, working class, trade unions, $P S O E$, industrial restructuring.

\section{INTRODUCCIÓN}

En los primeros meses de 1983, la movilización de un pueblo valenciano, Sagunto, que se opuso al cierre de una de las cabeceras de la empresa siderúrgica Altos Hornos del Mediterráneo (AHM) auspiciado por el Gobierno del Partido So- 
cialista Obrero Español (PSOE), tuvo un seguimiento tan amplio y se expresó con tanta virulencia que superó, con creces, el marco geográfico de la propia localidad y su provincia.

Se puede entender la magnitud del conflicto si nos atenemos a la duración del mismo, 430 días, y por lo acontecido en ese periodo. Así, se dieron 9 huelgas generales en la comarca del Camp de Morvedre, cuya capital es Sagunto, 24 huelgas en la fábrica - cerca de 2 millones de horas perdidas-, 11 manifestaciones en Valencia, 7 marchas a Madrid, 80 días de no acatamiento de las órdenes de cierre de instalaciones dadas por la Dirección de la empresa y varias semanas de incumplimiento de sus mandatos, "retenciones» de directivos de AHM y de los parlamentarios de las Cortes valencianas, asiduos cortes de tráfico y barricadas, recogida de 700.000 firmas para una Iniciativa Legislativa Popular, asalto a la comisaría de Sagunto tras ser herido un trabajador por el disparo de un policía, etc.

El detonante de este proceso fue una iniciativa del Gobierno socialista tendente a adecuar la estructura industrial española a las necesidades que demandaba la economía de mercado. Dicha imposición venía condicionada por una caída pronunciada del consumo, producto de la crisis económica, y por un sostenimiento de los niveles de producción, al mantenerse la capacidad instalada, propiciando un notable desajuste entre oferta y demanda ${ }^{1}$.

La caída de las principales magnitudes económicas en España desde los años setenta formaba parte de una recesión que afectaba a la mayoría de los países capitalistas, aunque tuvo unos efectos más devastadores en nuestro país debido a la debilidad en infraestructuras productivas, a un desarrollo industrial poco diversificado y a una escasa competitividad con respecto a las naciones más desarrolladas, como causas más destacadas.

Esta situación de claro retroceso económico coincidió con el inicio de la denominada transición a la democracia tras la muerte del dictador Francisco Franco en noviembre de 1975. Además de las incertidumbres políticas que ocasionó la sustitución de las instituciones franquistas, se unía el recrudecimiento de la lucha de clases que se venía desarrollando desde los primeros años de dicha década. Todo ello propició un retraso considerable en la aplicación de políticas de ajuste industrial en comparación con los países más industrializados, particularmente en la disminución de la capacidad de producción y en la reducción del empleo.

En esta tesitura, los diferentes gobiernos de la Unión de Centro Democrático (UCD), en el periodo 1977-1982, no fueron capaces de implementar unos planes de reconversión que los empresarios nacionales e internacionales urgían. De hecho, no fue hasta la llegada al poder del gabinete socialista cuando se acometió

1 Véase, entre otros, MARÍN, J. Mํa: «La fase dura de la reconversión industrial: 1983-1986», Historia del Presente, no 8 (2006/2); NAVARRO, M.: Política de reconversión: balance crítico, Madrid, EUDEMA, SA, 1990; y OLMOS, M.: Breve historia de la siderurgia saguntina. La batalla de A.H.M., Fernando Torres-Editor SA, Valencia, 1984. 
una profunda reestructuración del sector industrial y, concretamente, del siderúrgico ${ }^{2}$.

Frente a estos proyectos, la Unión General de Trabajadores (UGT) y las Comisiones Obreras (CCOO), así como el Partido Comunista de España (PCE), expresaron su oposición debido a las repercusiones que tendría sobre el empleo y las condiciones de vida. Rechazo que se concretaba, fundamentalmente, a través de la exigencia de una negociación de dichos planes que incluyera la garantía, en todo caso, de que la eliminación de puestos de trabajo fuera voluntaria y con la mayor indemnización posible.

Este tipo de oposición se impuso durante las protestas contra la clausura de la cabecera de AHM. La consumación del mismo fue que, pese a la determinación mostrada por la plantilla y el resto del pueblo saguntino, y la amplia solidaridad mostrada por buena parte de la ciudadanía española, no se pudo evitar el mencionado cierre. La razón fundamental, esgrimida por el que fuera presidente del Comité de Empresa (CE) de AHM, Miguel Campoy, se debió a que «nos hemos encontrado en inferioridad de condiciones respecto del Gobierno Central, pero esa situación ha tenido y tiene su explicación en la actitud permanentemente mantenida por el Consell [valenciano], bendiciendo lo que por arriba se les indicaba»³.

\section{CONTEXTO ECONÓMICO, POLÍTICO Y SOCIAL}

En el ámbito económico, la comarca del Camp de Morvedre, con una población cercana a los 70.000 habitantes, basaba sus ingresos en la agricultura -principalmente cítricos-y la siderurgia. Dos sectores, por otro lado, que atravesaban grandes dificultades para salir adelante.

A los problemas existentes en cuanto a la exportación de naranjas en un contexto generalizado de descenso del consumo, agravados por las restricciones comerciales que se aplicaban desde la Comunidad Económica Europea, hay que añadir la desaparición de 18.000 hanegadas de agrios, como consecuencia de las expropiaciones que se estaban llevando a cabo para la construcción de una nueva planta siderúrgica y de la autopista del Mediterráneo.

A su vez, se sumaba la delicadísima posición de un sector industrial basado esencialmente en la siderurgia, con una variada gama de pequeñas y medianas empresas concentradas en Sagunto y Puerto de Sagunto, de las que una gran parte de ellas estaban vinculadas a AHM, hasta el punto de que, en ambas localidades, se ubicaba el 75 por ciento de las empresas y trabajaba el 85 por ciento de la plantilla industrial. Finalmente, al objeto de completar esta breve radiografía local,

\footnotetext{
2 Véase NAVARRO, M., op. cit., pp. 115/6.

${ }^{3}$ Citado en OLMOS, M., op. cit., p. 90.
} 
el número de parados en la zona, en 1983, ascendía a unos 8.000 parados (más de un 40 por ciento), siendo el más alto de la región valenciana.

Siquiera brevemente, conviene detenerse en la evolución de algunas magnitudes económicas en los años objeto de estudio, con el fin de tener una visión más global y certera del momento. Desde 1977 hasta 1983, el paro creció cerca de un $11 \%$, superando los dos millones de personas, perdiéndose alrededor de un millón doscientos mil puestos de trabajo. Además, la cobertura del desempleo en 1983 alcanzaba únicamente a uno de cada tres parados, el gasto por protección social estaba a diez puntos de la media europea y más del $80 \%$ de las pensiones se encontraban por debajo del salario mínimo ${ }^{4}$.

En lo concerniente a la esfera política, las tradiciones históricas de la clase trabajadora en general y las coordenadas locales en particular fijaban rasgos comunes y específicos en los procesos políticos. Así, en cuanto a los resultados electorales desde las generales de 1977 hasta las municipales y autonómicas de 1983, se dan las siguientes cifras:

Cuadro 1. Resultados elecciones en Sagunto desde 1977 hasta 1983 (\%)

\begin{tabular}{|l|c|c|c|c|}
\hline \multicolumn{1}{|c|}{ Elección } & AP+UCD & PSOE+PCE & Otros & Abstención \\
\hline Generales 1977 & $22,5(2,3+20,2)$ & $66(46,6+19,4)$ & 11,5 & 17,6 \\
\hline Generales 1979 & $26,6(1,9+24,7)$ & $64,5(38,1+26,4)$ & 8,9 & 29,6 \\
\hline Locales 1979 & $23,5(0+23,5)$ & $69,5(39,8+29,7)$ & 6,9 & 33,6 \\
\hline Generales 1982 & $21,3(14,5+6,8)$ & $73,8(63,3+10,5)$ & 4,9 & 16 \\
\hline Autonómicas 1983 & $19,7(17,9+1,8)$ & $65,5(42,1+23,4)$ & 14,7 & 35,4 \\
\hline Locales 1983 & $15,3(15,3+0)$ & $60,7(41+19,7)$ & 23,9 & 35,2 \\
\hline
\end{tabular}

Fuente: Archivo Histórico Electoral de la Generalitat Valenciana (AHEGV) (www.pre.gva.es), 7 de diciembre de 2010. Elaboración propia.

EI PSOE es la fuerza con más votos en todas las elecciones, no bajando del $40 \%$ salvo en dos comicios. Sin embargo, desde 1977 se produce una tendencia de claro descenso en los apoyos electorales a excepción de 1982. De hecho, no consigue llegar a los 13.633 votos de las primeras elecciones en ninguna otra más, sin contar los obtenidos en 1982.

${ }^{4}$ Datos entresacados, entre otras publicaciones, del Archivo Histórico Fundación Largo Caballero (AHFLC), Comisión Ejecutiva Confederal, Unión General de Trabajadores, «Carta-Circular a las Federaciones Estatales de Industria y a las Uniones Territoriales», adjuntando, entre otros, el documento elaborado por la CEC sobre un Programa de Reformas frente al Paro y la Crisis, 20 de septiembre de 1983; RODRÍGUEZ, J.: «El período de la transición política desde la perspectiva del análisis económico», en TEZANOS, J. F., COTARELO, R. y DE BLAS, A. (eds.): La transición democrática española, Madrid, Editorial Sistema, 1989, pp. 117-147; MARÍN, J. M르: Los sindicatos y la reconversión industrial durante la transición, Madrid, Consejo Económico y Social, 1997; GARCíA, A. et alii: El trabajo en España: empleo y salarios, Barcelona, Ediciones Orbis, 1985. 
EI PCE es la segunda formación en número de votos salvando los años 1977 y 1982 , obteniendo una media de apoyo por encima del $20 \%$. Crece en número de sufragios en las elecciones generales de 1979 pero desciende significativamente en las municipales, en las que pasa de 7.812 en las de 1979 a 5.226 en las de 1983.

Los resultados electorales de la derecha estatal, sumando los de la extinta UCD y los predecesores del actual Partido Popular, Alianza Popular, no alcanzan el 27\%, reflejando su escaso tirón electoral. Solo en las generales de 1979 superará los 7.000 votos $^{5}$.

No obstante, si efectuamos una comparación global de los resultados con otras zonas del país con unas características socioeconómicas similares, los guarismos apenas se diferencian.

Cuadro 2. Resultados elecciones generales 1982 en zonas afectadas por la reconversión industrial (\%)

\begin{tabular}{|l|c|c|c|}
\hline & Total población & Conjunto trabajadores & Zonas afectadas \\
\hline PSOE & 48,4 & 59,1 & 50,6 \\
\hline AP-PDP & 26,2 & 10,1 & 6,8 \\
\hline UCD & 7,1 & 2,9 & 4,6 \\
\hline PCE & 4,1 & 11,0 & 21,9 \\
\hline CDS & 2,9 & 2,3 & 2,2 \\
\hline Otros partidos & 11,3 & 14,6 & 13,9 \\
\hline
\end{tabular}

Fuente: AHFLC, Comisión Ejecutiva Confederal, «Informe de 1983 relativo a los resultados de una Encuesta solicitada por UGT sobre la conflictividad ante la reconversión industrial, a través de la empresa Equipo de Investigación Sociológica, en las zonas más afectadas (Ferrol, Vigo, Gijón-Avilés, margen izquierda Bilbao, Bajo Llobregat, Sagunto, Getafe-Villaverde y Cádiz) y entre trabajadores metalúrgicos».

Por otro lado, la militancia más activa se encontraba nucleada en torno al PCE, con una influencia apreciable en la plantilla de AHM y, por ende, en la comarca. De hecho, el 60\% de los trabajadores de la planta siderúrgica estaban afiliados a CCOO en los inicios de la reconversión, aunque solo una pequeña parte mantenía la doble militancia. Ahora bien, la mayoría de los líderes sindicales pertenecían a dicho partido: en el I Congreso de CCOO del Pais Valencià, 1978, de 12

${ }^{5}$ Los datos sobre el número de votos se encuentran en el Archivo Histórico Electoral de la Generalitat Valenciana (AHEGV) (www.pre.gva.es), 7 de diciembre de 2010. 
miembros del Secretariado, 10 eran del PCE, y de los 23 componentes de la Comisión Ejecutiva, al menos 19 se encuadraban en el mismo ${ }^{6}$.

En el caso de la UGT, no sólo era inferior en afiliación con respecto a CCOO sino también en representación sindical: UGT tenía 11 delegados en 1980 y aumentará a 12 en 1982, mientras que CCOO partía de 23 delegados y subirá a 24 en 1982. En el año 1983, CCOO tenía 19 de los 29 delegados existentes ${ }^{7}$.

Ahora bien, estas tendencias sindicales tampoco parecen variar sustancialmente con las existentes en otras zonas con destacada presencia industrial en aquel periodo. Así, CCOO obtenía un 41,9\%, UGT, 31,2, USO, 3,5, no afiliados, 4,8 , nacionalistas, 6,7 , y otros sindicatos, $12,2^{8}$.

En cuanto al contexto social, la composición de la sociedad saguntina venía determinada por la preponderancia de los sectores económicos más arriba citados. Por una parte, en el agrícola, además de la existencia de pequeños propietarios venidos a menos por las dificultades de sobrevivir en un mercado cada vez más competitivo, agudizado por el acusado empeoramiento económico, abundaba la mano de obra asalariada como consecuencia de que el cultivo de los cítricos admitía escasos procedimientos mecánicos.

Por otra parte, en AHM, en 1983, trabajaban algo más de 4.000 operarios. Si cifrásemos en cuatro/cinco personas la media de una familia de la época —con las salvedades propias de una extrapolación realizada groso modo-, nos situaríamos en torno a las 20.000 personas directamente dependientes de la empresa siderúrgica, lo que supondría más de un $25 \%$ de la población de la comarca.

A estos dígitos, se deben añadir unas expectativas de mejora cada vez menores y una percepción generalizada de que todo el engranaje socioeconómico se desmoronaba a velocidad de vértigo, tal y como se reflejaba en las encuestas. Así, a la pregunta de «se ha hablado últimamente de la posibilidad de crear puestos alternativos de trabajo en Sagunto. ¿Qué piensa Vd. sobre ello?», sólo un 10\% pensaba «que con más o menos rapidez se crearán nuevas empresas», frente a un $67 \%$ «que son simples palabras para apaciguar a los trabajadores» y un $17 \%$ «que la realidad se impondrá y será muy difícil llevar esta medida a la práctica».

6 SOLER, J. LI. y SAZ, I.: «De lo Rat Penat al Congreso de Castellón. Las Comisiones Obreras en el País Valenciano (1966-1978)», en RUIZ, D. (dir.): Historia de Comisiones Obreras (1958-1988), Madrid, Siglo XXI de España Editores, 1993, pp. 311-312.

7 Datos extraídos del Archivo Historia del Trabajo Fundación 1ํ de Mayo (AHT). El Metalúrgico, nos 21 y 22 , enero y mayo de 1984 , pp. 25 y 11 respectivamente.

8 Datos extraídos del AHFLC, Comisión Ejecutiva Confederal, «Informe de 1983 relativo a los resultados de una Encuesta solicitada por UGT sobre la conflictividad ante la reconversión industrial, a través de la empresa Equipo de Investigación Sociológica, en las zonas más afectadas (Ferrol, Vigo, Gijón-Avilés, margen izquierda Bilbao, Bajo Llobregat, Sagunto, Getafe-Villaverde y Cádiz) y entre trabajadores metalúrgicos».

${ }^{9}$ ENCUESTA DEL CIS. Estudio marginal de Sagunto E.1.362 (Área Sagunto), julio/agosto 1983, p. 9. 
A su vez, las esperanzas depositadas como consecuencia de la llegada al poder del PSOE comenzaron a verse truncadas en febrero de 1983 por el anuncio de cierre de la cabecera. «De las siguientes frases, que le voy a leer, me gustaría que me dijese si está más bien de acuerdo o en desacuerdo». En la de las «medidas adoptadas por el Gobierno van contra las promesas electorales del PSOE y son una burla para los que le han votado", estaba un $68 \%$ de acuerdo y sólo un $16 \%$ en desacuerdo. En cuanto a otra consistente en que el «Gobierno ha actuado de forma despótica, sin importarle que gran parte del pueblo de Sagunto quede sin trabajo", estaba de acuerdo un $74 \%$ y un $16 \%$ en contra ${ }^{10}$.

\section{ORGANIZACIÓN Y COMIENZO DE LA LUCHA}

Una primera aproximación nos lleva, instantáneamente, a subrayar la impresionante participación de toda la población, expresándose en una asistencia masiva a las asambleas, en la proliferación de organismos que agrupaban a los distintos componentes de la lucha (plantilla, mujeres, jóvenes, estudiantes) y la infinidad de actos secundados por la casi totalidad de los habitantes del pueblo durante el conflicto ${ }^{11}$.

A lo largo de la lucha, hubo, fundamentalmente, dos pilares sobre los que bascularon las acciones de los trabajadores y del resto del pueblo. El primero fue el $\mathrm{CE}$, controlado por el sector moderado de CCOO, que contó con la confianza de buena parte de la plantilla y de sectores amplios de la comarca. Durante el tiempo que duró la protesta, se vio sometido a fuertes presiones de la empresa y del Instituto Nacional de Industria (INI), de las federaciones estatales del metal de los sindicatos mayoritarios y de los trabajadores, propiciando serias desavenencias en su seno y continuos enfrentamientos con la Coordinadora Sindical (CS).

El segundo fue la propia CS, que agrupaba a CCOO, UGT y CNT-AIT, apoyada por prácticamente todo el espectro sociopolítico de la zona. El sindicato con más presencia era CCOO que, en el ámbito comarcal, estaba dominado por la fracción que exigía una política más combativa contra el Gobierno. Su funcionamiento tenía su máxima expresión en la asamblea del pueblo, en donde se debatían las propuestas que emanaban de la propia CS, además de las que podían surgir de otros organismos creados ad hoc y a título individual. Su protagonismo fue innegable aunque en el último periodo descendió claramente por las crecientes diferencias habidas en el seno del PCE:

«En una primera etapa del conflicto se dio demasiado protagonismo a la Asamblea del pueblo, en detrimento de la fábrica y de la Dirección sindical... La Dirección sindical del conflicto debe ser fundamentalmente de los Sindicatos y de los Comités afectados dentro de las empresas, y aunque se deben establecer

10 Idem, p. 9

11 Véase una explicación más detallada y prolija en OLMOS, M., op. cit., pp. 63-4. 
mecanismos de discusión, coordinación con el resto de los sectores, estos nunca pueden llevar a que sean los sectores ciudadanos los que dirijan el conflicto, entre otras cosas porque desconocen los mecanismos internos y los límites de una lucha y una negociación» ${ }^{12}$.

Tras la declaración del Gobierno sobre el cierre de la cabecera el 4 de febrero de 1983, UGT y CCOO criticaron con firmeza tanto la fecha elegida, unos días antes de que aquél presentara su plan de reindustrialización, como el lugar donde se había tomado dicha decisión, al margen de la Comisión de Seguimiento establecida por anteriores acuerdos y compuesta por representantes de las Administraciones Públicas y de los sindicatos.

Obviamente, los líderes sindicales exigían, con todo el derecho, explicaciones e información precisa sobre los planes gubernamentales, dado que atañían directamente a los trabajadores. Ahora bien, ¿debía convertirse en el punto central de la oposición sindical? ¿Acaso una medida como el cierre de la cabecera de AHM requeriría una contestación muy diferente dependiendo del lugar y la fecha en que se difundiera?

De todas formas, se levantó tal indignación en el pueblo que la empresa se vio obligada a posponer temporalmente el cierre, sin que ello frenara las movilizaciones ya convocadas. Así, el 16 de febrero, se convoca la primera huelga general en el Camp del Morvedre, siendo secundada de manera masiva, además de en Sagunto, en otros pueblos de la comarca como Estivella, Canet y Gilet, culminando, por la tarde, en una manifestación cuya asistencia fue cifrada por la policía municipal en más de 30.000 personas.

Diez días más tarde, los trabajadores aprueban, tras una multitudinaria asamblea, la realización de un encierro con carácter indefinido en la empresa. Asimismo, se decide ir el 28 de febrero a la sede de las Cortes valencianas, en protesta por la actitud mantenida por el Gobierno socialista de la Generalitat valenciana en relación al cierre de AHM.

Cerca de varios miles de trabajadores y sus familias estuvieron concentrados desde las doce de la mañana en las puertas de las Cortes impidiendo la salida de los diputados regionales hasta pasadas las once de la noche. Hay que señalar que esta protesta fue apoyada por la totalidad de los partidos, sindicatos y organizaciones ciudadanas de Sagunto, incluido el PSOE. De hecho, su organización del Camp de Morvedre - cuyo líder era Manuel Girona, presidente de la Diputación de Valencia- apoyó sin ambages las movilizaciones.

$12 \mathrm{AHT}$, «Altos Hornos del Mediterráneo: Las enseñanzas de una lucha», El Metalúrgico ํㅜ 22, mayo 1984, p. 12, sin firma. 


\section{ESTRATEGIA GUBERNAMENTAL VERSUS ESTRATEGIA SINDICAL}

El Gobierno, apoyado por los grandes empresarios y banqueros en esta cuestión, procuró que la división entre las plantillas de los sectores afectados, así como entre las organizaciones que lideraban la protesta, se extendiera como una mancha de aceite. Se trataba de evitar la unificación de AHM con las plantas de Altos Hornos de Vizcaya (AHV) y de Ensidesa en Asturias. Focalizar separadamente cada factoría e independizar sus reivindicaciones le permitiría ejecutar sus planes con una menor protesta social y, por ende, aplicarlos con una mayor efectividad. Esta posición era tan evidente que los líderes sindicales reconocieron que «hay un hecho cierto que nos debe hacer reflexionar y es que a lo largo del conflicto la actuación y solidaridad sectorial ha sido nula» ${ }^{13}$.

De este modo, los sindicatos de clase y el PCE publicaron comunicados y convocaron huelgas y manifestaciones con objetivos estrictamente localistas, hasta el punto de defender posiciones diametralmente opuestas dependiendo del lugar en que se encontraran. Cuanto menos resultaba muy chocante que, en el seno de estas organizaciones de clase, las posturas político-sindicales estuvieran más cerca de los intereses patronales y de la derecha de sus respectivos ámbitos geográficos que de sus propios compañeros en la organización que militaban. Así, mientras UGT, CCOO, el PCE y sectores del PSOE saguntino articulaban una respuesta común con la derecha política y los grandes empresarios valencianos en las reivindicaciones y en su vertebración ${ }^{14}$; UGT, CCOO, el PCE y sectores del PSOE asturiano se unían, a su vez, con la derecha económica y política asturiana.

La reconversión repercutía no solo al sector siderúrgico, sino a la estructura industrial del país, por consiguiente, la unificación de las plantillas involucradas parecía ser un paso ineludible si se quería paralizar dicho plan. Cuestión que, ni mucho menos, iba a ser sencilla. Si se intentaba defender los puestos de trabajo debería acometerse una profunda reorganización del aparato industrial, que supondría invertir una gran cantidad de dinero con el fin de garantizar su viabilidad ${ }^{15}$. Asimismo, dicha reconversión se rechazaba porque se hacía a costa de los trabajadores y no en función de los intereses de la mayoría de la sociedad. Sin embargo, la confrontación política y sindical estuvo ocupada por quién se llevaba las

13 Ídem, p. 12.

14 De hecho, así se expresaba el diputado de Alianza Popular en las Cortes valencianas, Manuel Giner Miralles: «¿Qué vamos a hacerle a esta coincidencia con el PCE? No tiene trascendencia, porque por encima de las ideologías está la defensa de los intereses valencianos y tenemos que ir codo a codo con quien sea defensor de estos intereses irrenunciables", en declaraciones aparecidas en El País, 6 de marzo de 1983, (www.elpais.com), (7 de diciembre de 2010).

15 « ¿Y por qué cree Vd. que se pierde dinero en Altos Hornos del Mediterráneo?». La mayoría de la población, el $78 \%$, se concentraba en tres respuestas: «Por la antigüedad y falta de renovación de sus instalaciones» $\mathrm{y}$ «por no haberse completado nunca el proyecto de siderurgia integral con bandas en frío y en caliente», $31 \%$ cada una, y «por la mala organización de la empresa», un 16\%, en ENCUESTA DEL CIS, op. cit., p. 6. 
inversiones a su zona o qué factoría debía acometer medidas más duras al soportar más cargas financieras, entre otras de similar calibre.

¿Qué pensaban al respecto los trabajadores del sector sobre cómo lograr cambiar los planes del Gobierno? «Si en un plan de reconversión industrial las negociaciones llegaran a un punto muerto, ¿con cuál de las dos siguientes actuaciones estaría Vd. más de acuerdo? Seguir negociando y buscando nuevas propuestas aunque hubieran de hacer los trabajadores alguna concesión» -lo apoyan un $35,2 \%$ - mientras que «presionar al máximo a los empresarios mediante huelgas, manifestaciones y otras acciones de lucha», lo defienden un $61,7 \%$. Asimismo, se apunta que «esta actitud de movilización ante un punto muerto en las negociaciones siguen siendo mayoría los electores de CCOO $(75,1)$ y de INTG [la Intersindical, central sindical gallega de orientación nacionalista] $(85,7)$, pero también se observan importantes sectores de UGT que se inclinan por esta opción (el $56,3)$, de USO $(56,3)$, de electores de delegados no afiliados $(72,7)$ y de otros sindicatos $(54,6) \gg{ }^{16}$.

\section{LA REBELIÓN PROSIGUE}

A primeros de marzo, el Presidente de AHM ordena reducir la producción en un 20 por ciento en aras a lograr, de manera paulatina, el declarado cierre de la cabecera. Dicha medida se contesta inmediatamente con una huelga de trabajo lento que, una semana después, consigue que la factoría recupere su nivel habitual de producción. Se da un ultimátum a la plantilla a que deponga su actitud, hecho que no se produce. Nos hallábamos ante un cuestionamiento del principio de autoridad intrínseco al funcionamiento del sistema capitalista, dado que las decisiones trascendentales de la factoría comenzaban a ser tomadas por la plantilla.

Ante el cariz que estaban tomando los hechos, el Presidente de AHM, el 18 de marzo, visita personalmente el Puerto de Sagunto, con el fin de ordenar a los trabajadores que depongan sin dilación su comportamiento. Marcará, para ello, un plazo máximo de tres días, produciéndose una peculiar conclusión:

"Cerca de 25.000 personas rodean ese día las dependencias del casino, donde el presidente de AHM se encuentra reunido con el Comité de Empresa, reteniéndole durante doce horas sin poder salir, hasta que consigue ser rescatado por la policía, contando con la ayuda de los miembros del Comité de Empresa que intentaron apaciguar los ánimos en el pueblo El conflicto se resolvió al tomar la empresa la decisión de dejar en suspenso la orden de reducción del 20 por ciento, accediendo los trabajadores a una merma de producción del 12 por ciento » ${ }^{17}$.

${ }^{16}$ Véase AHFLC, Comisión Ejecutiva Confederal, «Informe de los resultados de la Encuesta sobre la conflictividad...», op. cit., pp. 11/2.

17 OLMOS, M., op. cit., p. 65. 
Sin dejar de movilizarse durante los meses precedentes, el 14 de junio se manifiestan en Madrid ante la sede del Ministerio de Industria y Energía, acompañándose de una huelga general de 48 horas en Sagunto. Acuden alrededor de siete $u$ ocho mil personas, que son reprimidas de manera contundente por las fuerzas de orden público, saldándose los enfrentamientos con siete manifestantes heridos $^{18}$. Como consecuencia de los graves incidentes ocurridos y ante la inminencia del desacuerdo en la Comisión, las protestas arrecian considerablemente.

De hecho, el día 2 de julio, los saguntinos efectúan cortes de carretera y de vías férreas de manera espontánea y con tanta virulencia que desbordan las directrices que emanaban de la CS, que había convocado pequeños cortes de tráfico para distribuir hojas informativas ${ }^{19}$. Al día siguiente, en una asamblea tan concurrida que se llena el campo de fútbol de la localidad, se decide efectuar otra huelga general de 48 horas en Sagunto para los días 4 y 5, con una manifestación este último día, terminada la cual emprenderían viaje a Madrid.

Además del gran despliegue que plasman los trabajadores de Sagunto en Madrid el 6 de julio, la solidaridad que generan es de tal calibre que más de 20.000 madrileños acuden a la manifestación que recorrerá varias calles céntricas en dirección a las Cortes españolas, en donde, ese mismo día, se aprobaba el decreto ley de reconversión de la siderurgia integral que suponía, en la práctica, la desaparición de la factoría.

Poco antes de concluir los meses estivales, la dirección de la factoría da un paso adelante con el fin de cumplimentar los planes previstos. Prescribe, de esta guisa, parar un tren estructural y, al mismo tiempo, notificar a 160 trabajadores que se incorporen a otras secciones de la factoría debido a la no puesta en marcha del mismo. Comienza lo que se conocerá como «la batalla del tren $28 »$.

EI CE emite su opinión de rechazo tres días después de conocida la medida y convoca a la plantilla a una asamblea para el día 14 de septiembre, donde se aprobará poner en funcionamiento el tren 28 en un claro desafío a las órdenes empresariales. Ante diversos medios de comunicación, el CE informa de que unos raíles pedidos por RENFE han sido fabricados de manera «autogestionaria». Se trataba, nuevamente, de una alteración grave del funcionamiento de la economía capita-

18 «La agresividad verbal y las tentativas de algunos manifestantes de cortar el tráfico rodado son rechazables pero no pueden justificar la dureza de los métodos empleados por los cuerpos de seguridad, a las órdenes de un Gobierno cuyos miembros pertenecen a un partido apellidado socialista y obrero... Los botes de humo o las porras son los peores procedimientos imaginables para convencer a unos trabajadores a quienes no cabe atribuir responsabilidad por la eventual inviabilidad de la planta de Sagunto, y que pagarán el precio de la dejación de algunos profesionales de la empresa pública que continúan, sin embargo, mereciendo la confianza del Gobierno y que no han rendido cuentas a nadie por sus erróneas decisiones", editorial de El País, 16 de junio de 1983, (www.elpais.com), (7 de diciembre de 2010).

19 Véase El País, 3 de julio de 1983, (www.elpais.com), (7 de diciembre de 2010). 
lista, repitiéndose el procedimiento empleado cuando el incumplimiento de la orden de reducción de la producción en un 20 por ciento ${ }^{20}$.

La respuesta del Presidente de AHM fue inmediata y acorde con la gravedad de los eventos ocurridos. Así, se envían cartas de despido a 69 trabajadores y se expedientan sin empleo y sueldo a 158 trabajadores por incumplir el traslado de sección ${ }^{21}$, contando con el respaldo del INI y el Gobierno. El 21 de septiembre, a las diez de la noche, se celebra una asamblea en la que se decide continuar trabajando en el tren del 28, aún contando con el mantenimiento de las medidas disciplinarias. Dos horas después, se reúnen el Conseller de Industria de la Generalitat valenciana, que ejerce como mediador, la representación sindical y la dirección empresarial, acordándose que los trabajadores abandonarían el tren estructural a cambio de que la empresa levantara los despidos.

Sin embargo, el pacto estuvo caminando sobre el filo de una navaja en aquellas horas. Tanto es así que, en la asamblea congregada a tal efecto, hubo bastante oposición al compromiso suscrito. La intervención más aplaudida la hizo un trabajador al incidir en que «si cedemos, jamás podrán trabajar los jóvenes, será la muerte lenta de $A H M »{ }^{22}$. Teniendo en cuenta los ánimos de los allí presentes, el presidente del CE abogó porque solo pudieran votar los trabajadores de AHM, impidiéndose, por vez primera, la participación de las mujeres y de los jóvenes sin trabajo ${ }^{23}$. La propuesta del CE fue aprobada aunque, obviamente, no se sabrá qué resultado se hubiera dado en la votación con el concurso de todos los colectivos implicados.

Conviene especificar que la explicación de este cúmulo de actos no es suficiente para comprenderlos íntegramente. Se dieron una serie de rasgos que fueron moldeando los contenidos y las formas de las movilizaciones. Fisonomía, por otra parte, que venía mediatizada por la implicación directa del pueblo en la defensa de las condiciones de trabajo presentes y en la configuración de un futuro con menos interrogantes.

Para ello, es menester incidir en que, una victoria electoral como la obtenida por el PSOE en el año 1982, se debió a un apoyo social muy extenso y, por ende, bastante heterogéneo. Esta característica, asimismo, es perfectamente compatible con el planteamiento de que, por parte de las clases trabajadoras, dicho apoyo fue mayoritario y provisto de grandes dosis de confianza. En el Camp de

20 «La situación ha sido definida por fuentes oficiales de este modo: "El Comité de Empresa dirige de hecho la factoría de Sagunto" ", en El País, 20 de septiembre de 1983, (www.elpais.com), (7 de diciembre de 2010).

21 Según LASO, R., Breve historia de la siderurgia integral española 1901-2002, Centro de Estudios e Investigaciones Sociales de la Industria (Federación Minerometalúrgica de CCOO), www.minerometal.ccoo.es, op. cit., pp. 28/9. No obstante, en OLMOS, M., op. cit., pp. 66/7, los despedidos son 80 y los sancionados, 160.

22 El País, 25 de septiembre de 1983, (www.elpais.com), (7 de diciembre de 2010).

23 «(...) en los dirigentes sindicales apareció el temor de que la situación fuese nuevamente desbordada, que aquella asamblea les arrastrara hacia un callejón sin salida», El País, 25 de septiembre de 1983, (www.elpais.com), (7 de diciembre de 2010). 
Morvedre, precisamente, los resultados electorales ratifican dicho aserto: De los 42.220 votos realizados a candidaturas, en un censo electoral de 51.093 personas, el PSOE recibió 25.642 apoyos, es decir, un $61 \%$ del total ${ }^{24}$.

Este escenario, no obstante, comenzó a verse trastocado por las medidas propuestas por la dirección socialista. Así, tuvieron que oponerse a unas políticas que, en el caso de la reconversión industrial diseñada, significaban un deterioro considerable de sus condiciones de vida, mientras que, por otra parte, no percibían esa misma determinación para con los sectores sociales y económicos más pudientes ${ }^{25}$. Además, dichas acciones se daban de bruces con lo explicitado en su programa electoral y con su labor de oposición contra los anteriores gobiernos de la UCD ${ }^{26}$.

Hay que añadir, en este orden de cosas, las controvertidas relaciones mantenidas entre los líderes sindicales y políticos de la protesta y los colectivos sociales involucrados en la misma, esbozadas anteriormente, en unos momentos caracterizados por la angustia y la zozobra sobre su porvenir. Así, al formular que «(...) Ante los planes de reconversión industrial y otros conflictos, ¿qué sindicato cree Vd. que está actuando mejor? », figuraba que CCOO obtenía un 31,8 por ciento y UGT, un 24,5 , dando un total del 56,3 , a la vez que, un 23,8 pensaban que ningún sindicato estaba actuando bien ${ }^{27}$, lo que significa que, según el Informe ya citado solicitado por la UGT en el que se hacía referencia a los resultados de las elecciones sindicales, CCOO reducía su aprobación en cerca de 10 puntos porcentuales y UGT disminuía, a su vez, en casi 7.

Asimismo, hay que tener en cuenta la precaria situación económica del país y, en concreto, de la zona, expresándose por medio de un paro que crecía rápidamente, de unos salarios que venían perdiendo poder adquisitivo desde hacía ya varios años ${ }^{28}$, con una jornada laboral de las más altas entre los países más desarrollados y con un Estado del bienestar muy raquítico en función de las amplias necesidades a satisfacer, entre otros condicionantes.

24 AHEGV, (www.pre.gva.es), 7 de diciembre de 2010.

25 Se pueden citar, a modo de ejemplo, las tensiones que hubo en el gabinete de Felipe González acerca de cómo abordar los privilegios de las rentas del capital con respecto a las del trabajo. De hecho, el primer proyecto provocó una crisis en el equipo económico del PSOE y fue desechado por las críticas que provocó en la patronal. El segundo texto también fue desestimado por no ajustarse aún a las peticiones de los grandes empresarios. Tras varias cenas y reuniones ad hoc, el proyecto de ley resultante contenía una serie de artículos que coincidían, prácticamente en su totalidad, con el contenido del informe —páginas 44 y siguientes - presentado por el presidente de la Asociación Española de Banca en su asamblea.

${ }^{26}$ Véase NAVARRO, M., op. cit., p. 125. Es más, el drástico ajuste salarial preconizado por los miembros del PSOE se contradecía con lo explicitado en su programa electoral de 1982, página 7, al defender que «(...) Los acuerdos salariales anuales deben garantizar el mantenimiento del poder adquisitivo».

27 AHFLC, Comisión Ejecutiva Confederal, «Informe de los resultados de la Encuesta sobre la conflictividad ante la reconversión industrial...», op. cit.

28 «El desempleo masivo y el autoconvencimiento del colectivo de trabajadores acerca de las buenas condiciones retributivas previamente alcanzadas hicieron posible la asunción pactada de una política de rentas que, en términos prácticos, ha congelado hasta 1984 los salarios reales al nivel de 1980», en ESPINA, Á.: «La política de rentas en España: 1977-1986», en GARCÍA, A. et alii, op. cit., p. 177. 
A modo de conclusión, hay que subrayar, por un lado, la actuación desproporcionada que llevaron a cabo las fuerzas de orden público contra las movilizaciones. Y, por otro lado, la información suministrada por buena parte de los medios de comunicación y por destacados líderes del PSOE contra la plantilla de AHM en particular y las del resto de los sectores incluidos en la reconversión industrial en general, achacándoles la práctica totalidad de los males que padecía la economía española ${ }^{29}$.

\section{LOS ÚLTIMOS EMPELLONES}

El 27 de diciembre, un trabajador de AHM, Manuel Tárrega, es herido por el arma de un policía durante un corte de tráfico efectuado en la autopista del Mediterráneo ${ }^{30}$. Por la tarde, la comisaría del Puerto de Sagunto es atacada por varios cientos de personas con todo tipo de objetos, desde piedras hasta bombonas de camping-gas, saldándose la refriega con 28 policías heridos, decenas de manifestantes contusionados y dos coches y una furgoneta de la Policía incendiados.

Dos días después, se presentará el expediente de regulación de empleo (ERE), cuya negociación se iniciaría el 4 de enero en lo tocante al personal ubicado en el horno alto número 2 con sus respectivos servicios auxiliares, esto es, una reducción de plantilla cifrada en un $15 \%$ del total.

En este orden de cosas, es importante enfatizar que esta medida del gabinete socialista coincide con un proceso de fuerte crispación social, cuyo punto de máxima ebullición se dio con las jornadas de lucha convocadas por CCOO y UGT contra la reconversión industrial los días 2 y 3 de febrero. Era la primera vez, tras un año jalonado de movilizaciones y protestas sectoriales y territoriales, que se daba una respuesta coordinada a escala estatal, aunque la convocatoria estuvo plagada de múltiples obstáculos y rencillas.

29 Percepción que, con respecto a los medios de comunicación, se expresa en la mencionada Encuesta del CIS: «¿Considera Vd. que los medios de comunicación han tratado con objetividad el problema de Sagunto, que han estado al lado de los trabajadores o por el contrario se han puesto al lado del Gobierno?» La mayoría, el 38\%, considera que «se han puesto del lado del Gobierno», un 27\% «han tratado con objetividad el problema» y sólo un $12 \%$ piensa que «han estado del lado de los trabajadores», p. 11. En cuanto a los miembros del PSOE, sobresalen, entre otras, las declaraciones de Enrique Múgica, entonces miembro de la Comisión Ejecutiva del PSOE y actual Defensor del Pueblo, planteando que las movilizaciones «contra la reconversión están presididas por la mala fe, la demagogia y un estricto sentido del gremialismo", en Cinco Días, 11 de febrero de 1984. Y, también, las de Carlos Solchaga, ministro de Industria, responsabilizando a los trabajadores del despilfarro económico de AHM porque «nos cuestan 10.000 millones de pesetas, además del salario que ganan», en unas Jornadas de Promoción Industrial organizadas por el PSOE el día 10 de febrero de 1984

30 El Gobierno Civil de Valencia difundió una nota oficial sobre los sucesos del día 27 en la que se expresa que «desde el primer instante calificamos de inaceptable el uso de armas de fuego en una situación como aquella, por las graves consecuencias que puede producir...", citada en El País, 28 de diciembre de 1983, (www.elpais.com), (7 de diciembre de 2010). 
Así, mientras CCOO pretendía que la jornada del día 2 se convirtiera en una protesta más generalizada contra la reconversión y en una forma de presión para la reapertura de negociaciones, UGT centraba sus objetivos en rechazar las rescisiones de contratos en los sectores propuestos para ser reconvertidos. Por si fuera poco, la diversidad de los actos de protesta fue la tónica dominante. En algunos lugares como Gijón, Puerto Real (Cádiz), Getafe (Madrid) y Camp de Morvedre la huelga fue general. En otros, como en Vigo, Ferrol, Cantabria, Andalucía y demás localidades incluidas en el proceso de reconversión industrial, se llevaron a cabo únicamente paros y manifestaciones. En zonas como Vizcaya y Cataluña, además, la jornada de protesta se trasladó al día 3 a petición de UGT. El resultado, finalmente, se saldó con una participación que rondó las 400 mil personas ${ }^{31}$.

Pero es que, junto a estas movilizaciones, había más de un millón de trabajadores a la espera de firmar sus convenios colectivos, paralizados por las fuertes discrepancias con directivos públicos y empresarios privados. De hecho, estos últimos trataban de empujar con fuerza al Gobierno para que prosiguiera con sus planes, los acelerase y, en todo caso, no cediera a la presión de los trabajadores. Así, a mediados de enero de 1984, alrededor de cuatro mil empresarios se concentraron en Madrid para expresar sus diferencias con determinados aspectos de la política económica gubernamental.

El 20 de febrero, bautizado como «día negro» por los saguntinos, la DGE autoriza el ERE que contempla la salida de la empresa de 155 trabajadores y la rescisión de contrato de más de 240 eventuales debido al cierre del horno alto número 2. Ese mismo día, el Presidente de AHM aplica la autorización administrativa con el cierre de dicho horno, el tren Blooming, así como los hornos de fosa. A su vez, cortará el suministro de coque, manteniendo el horno alto con un funcionamiento mínimo.

Ante esta situación, la asamblea de trabajadores aprueba, tras valorar detenidamente distintas variantes, una alternativa que conllevaba, en esencia, un nuevo incumplimiento de una decisión empresarial.

La empresa se esforzará por cortar otra indisciplina laboral, a la vez que amenaza con las consecuencias que se derivarían de la misma, ya que «constituiría un inconveniente objetivo para la atracción de nuevas industrias que se intentan ubicar en la zona y para el desarrollo de los trabajos que realiza en la actualidad la Comisión Mixta Administración Central-Generalitat de Valencia para la creación de empleos alternativos ${ }^{32}$.

Pese a las órdenes recibidas, la plantilla se decantará porque el horno siga encendido aunque fuera a ritmo lento. Sin embargo, el 28 de febrero, llegan las car-

31 AHT, Resolución del Consejo Confederal de CCOO del 7 al 9 de febrero de 1984, aparecida en Gaceta Sindical, no 0, Segunda Época, p. 49.

32 AHFLC, Comisión Ejecutiva Confederal, "Comunicado al Comité de Empresa de Altos Hornos del Mediterráneo (AHM), de la Dirección de AHM», sin fecha. 
tas de despido para los 155 trabajadores y la rescisión de los eventuales, lo que provoca la primera grieta digna de mención en el seno de la plantilla. De esta manera, el 1 de marzo, los 155 despedidos no entran a trabajar siguiendo instrucciones del CE, lo que no ocurre con los eventuales, quienes resuelven en asamblea hacer oídos sordos a la rescisión de sus contratos.

Esta panoplia de eventos tiene su cénit el 2 de marzo con la retención del jefe de personal de AHM durante seis horas por un nutrido grupo de operarios de la factoría. Después de mucha zozobra, innumerables llamadas telefónicas, insultos y amenazas, el INI acepta, con el fin de apaciguar aquel tumulto, que los despedidos se puedan incorporar al trabajo. Al día siguiente, se retractará al declarar nulas las concesiones hechas, argumentando que fueron producto de unas coacciones tildadas de intolerables.

Al igual que lo acontecido con el intento de reducción del $20 \%$ de producción y la batalla del tren estructural 28, el control de la empresa volvía a estar en manos de la plantilla, aun habiendo trascurrido un año entero de continuas protestas. Evidentemente, el nuevo «control» de la fábrica se daba en un contexto diferente, aunque solo fuera porque las fuerzas estaban llegando al límite y la desesperación crecía rauda y velozmente.

Al mismo tiempo que los trabajadores seguían sin claudicar, las direcciones sindicales proponían al presidente de AHM una negociación sin condiciones. Éste responderá que no habrá diálogo hasta que no se restituya su autoridad ${ }^{33}$. A su vez, el 12 de marzo de 1984, Miguel Campoy dirige una carta a Nicolás Redondo, por aquel entonces secretario general de UGT, expresando criterios que parecían ir por derroteros diferentes a las resoluciones aprobadas en las asambleas: «El Comité de Empresa al que represento es consciente de que sólo por la vía de una negociación abierta y responsable pueden resolverse de forma satisfactoria todos los problemas presentes y futuros ${ }^{34}$.

Pese a estos intentos, infructuosos por el momento, la empresa lanzará un ultimátum para que se clausure el horno alto o, de lo contrario, se efectuará un cierre patronal. Los trabajadores, mayoritariamente, reiteran su decisión de continuar el boicot, aún a sabiendas de que la vida de dicho horno se podría alargar como mucho un mes más.

En esta encrucijada, los días 22 y 23 de marzo, se remiten cartas de despido a 230 obreros. En esa tesitura, los sindicatos estimaban que las fuerzas de los trabajadores estaban prácticamente al límite, debido al asedio a que se estaban viendo sometidos, incluido el suministro de coque imprescindible para el funcionamiento del horno. Añadían, a su vez, que los 230 despidos significaban una cortapisa más para la movilización y que la amenaza de cierre patronal se convertía

33 Véase OLMOS, M., op. cit., pp. 72 y 73

34 AHFLC, Comisión Ejecutiva Confederal, «Carta del Presidente del Comité de Empresa a Nicolás Redondo". 
en una losa que podía sepultar la continuación de la lucha. De esta guisa, entendieron que lo más adecuado era poner el horno alto número 2 en posición de «banking» (el horno queda rebajado de temperatura, dejando de producir, aunque queda en una situación tal que permite ponerlo en marcha en cualquier momento, ya que su estructura no quedaría dañada), cerrar el tren «Blooming» y los hornos de fosa, a cambio de que la empresa levantara los despidos:

«Tras una tensa asamblea, donde quedaron de manifiesto la desesperanza, la rabia, el orgullo de "clase", la intransigencia del que no sabe perder, la serenidad de los que se saben vencidos, el odio hacia los que abusan del poder y el miedo al paro y a la miseria, se pasó a votar la propuesta que recibió el apoyo de 2.041 trabajadores, por lo que al día siguiente comenzaban a acatar las órdenes de la empresa» ${ }^{35}$.

El 4 de abril se firma un preacuerdo entre el INI, AHM, el CE y las federaciones del metal de CCOO y UGT, en el que se explicita el cierre definitivo de la cabecera de Sagunto el 1 de octubre de 1984, la creación de 2.100 puestos de trabajo alternativos hasta 1987 por parte del INI y el tratamiento de los «excedentes» de plantilla. Dicho preacuerdo queda pendiente de ratificación por el Consejo de Administración del INI y por los trabajadores.

Durante la asamblea celebrada el 5 de abril, se produjeron enfrentamientos virulentos entre los partidarios del preacuerdo y los opositores al mismo, incluyendo, en ambos bandos, a miembros del CE. Por parte de los sectores críticos, se presentó una propuesta de ratificación del acuerdo diferente al referéndum a realizar entre los operarios de AHM, consistente en la celebración de una asamblea del pueblo. Por el contrario, las posturas patrocinadas por el sector mayoritario de CCOO, con el apoyo de las direcciones del PCE y de la UGT, se basaban en que la decisión final sólo debía recaer en la plantilla.

De todas formas, parecía un tanto contradictorio que, de cara a secundar las huelgas, acudir a las manifestaciones, participar en los cortes de tráfico, recoger firmas, realizar viajes por toda la geografía española, entre otros actos, la colaboración de todo el pueblo se consideraba como vital, pero, a la hora de tomar decisiones trascendentales, su punto de vista no se tuviera en cuenta.

El referéndum tuvo una primera convocatoria para el 6 de abril aunque fue saboteado por trabajadores eventuales debido a que este colectivo - unos 700 - fue excluido de la votación. El CE responde posponiéndolo para el día 10, en donde se aprobará por 2.237 síes, 1.040 noes y 110 blancos y nulos, según los datos de El Metalúrgico de CCOO, n 22, de mayo de $1984^{36}$.

35 OLMOS, M., op. cit., p. 74.

36 Según OLMOS, M., op. cit., p. 78, las cifras depararon este resultado: 2.157 votos afirmativos, 1.033 negativos, 92 en blanco y 12 nulos. Como se puede comprobar, la tendencia fundamental no varía. 


\section{Cuadro 3. Resultados del referéndum por mesas, en número de votos y en porcentaje (entre paréntesis)}

\begin{tabular}{|l|c|c|c|c|c|}
\hline \multicolumn{1}{|c|}{ Mesas } & Censo & $\begin{array}{c}\text { Votos- } \\
\text { Participación }\end{array}$ & Síes & Noes & $\begin{array}{c}\text { Blancos } \\
\text { nulos }\end{array}$ \\
\hline Hornos de acero & 696 & $559(80,3)$ & 440 & 106 & 13 \\
\hline R. Subproductos & 492 & $411(83,5)$ & 332 & 66 & 13 \\
\hline Horno alto & 404 & $338(83,7)$ & 232 & 92 & 14 \\
\hline Taller eléctrico & 542 & $429(79,2)$ & 279 & 134 & 16 \\
\hline Taller general & 616 & $540(87,7)$ & 418 & 100 & 22 \\
\hline Laminación frío & 832 & $741(89,1)$ & 233 & 490 & 18 \\
\hline Oficinas generales & 313 & $276(88,2)$ & 220 & 45 & 11 \\
\hline Oficinas Madrid & 123 & $93(75,6)$ & 83 & 7 & 3 \\
\hline Total & 4.018 & $3.387(83,3)$ & $2.237(66,1)$ & $1.040(30,7)$ & $110(3,2)$ \\
\hline
\end{tabular}

Fuente: AHT, El Metalúrgico № 22 de mayo de 1984.

Siquiera brevemente, hay que valorar la votación tras cerca de quince meses del inicio del conflicto. El alto porcentaje de participación habido es un hecho innegable, con una tasa superior al $80 \%$, indicando la enorme importancia que le otorgaban los trabajadores. El que dos tercios de los votantes avalaran el preacuerdo otorgaba a éste una clara mayoría, que zanjaba la lucha e indicaba, al mismo tiempo, cómo encauzarla a partir de esos momentos. Asimismo, el que hubiera casi un tercio de la plantilla que se opusiera al acuerdo reveló la presencia aún de una fuerte oposición al mismo y a que la lucha concluyera, a pesar de los altos sacrificios que estaba comportado su sostenimiento. Los 700 eventuales excluidos no hubieran variado el resultado final pero sí habrían propiciado unos porcentajes diferentes a los que se dieron ${ }^{37}$.

37 «Mientras el presidente del Comité de Empresa de AHM, Miguel Campoy, declaró que el acuerdo alcanzado era la única salida posible en las actuales circunstancias, el portavoz de la Coordinadora Sindical de Sagunto, Ángel Olmos, realizó una valoración global del resultado del referéndum. "A los trabajadores", comentó Olmos, "se les ha llevado al terreno de esta decisión impuesta por los acontecimientos. Los 1.033 votos contrarios a la aceptación del acuerdo vienen a demostrar que un sector de la plantilla está por la defensa de la cabecera". Este sector piensa que el Gobierno debía haber tomado la decisión del cierre, pero nunca con el apoyo de los trabajadores. Para uno de los hombres que ha dirigido la larga lucha de AHM, los 2.157 votos afirmativos proceden de dos tipos de colectivos: de un lado, los que, "consciente o inconscientemente, han dado su respaldo al cierre", y de otro, "cerca de $1.000 \mathrm{com}$ pañeros de más de 52 años, que han visto en el acuerdo la mejor forma de resolver su supervivencia futura". Ángel Olmos se lamentó de la decisión de la asamblea de trabajadores por la que se impidió votar a unos 700 eventuales. "Este colectivo", afirmó Olmos, "podría haber inclinado la balanza en otro sentido"», en El País, 12 de abril de 1984, (www.elpais.com), (7 de diciembre de 2010). 


\section{CONCLUSIONES}

En esencia, el hilo conductor de aquellas movilizaciones era la defensa a ultranza de los empleos, sin embargo, parecía contener mayor enjundia. Se reivindicaba un futuro con más luces y menos sombras para la mayoría de los habitantes de la zona.

Ahora bien, dado que era determinante la conservación de los puestos de trabajo, la comprensión cabal de lo que se dilucidaba en realidad constituía el meollo del conflicto. Así, en el ámbito político, la exigencia de responsabilizar a los grandes empresarios y banqueros, junto a los gestores públicos, del desaguisado del sector siderúrgico - y de la crisis económica en su conjunto-, debía ir acompañada del rechazo a que los trabajadores fueran los que pagaran los platos rotos de la reconversión propuesta, convirtiéndose en los únicos que soportaran la crisis. Esta cuestión, claramente, tenía un doble efecto.

Por un lado, los gobiernos del PSOE, tanto a escala estatal como autonómica y local, acusaron en innumerables ocasiones a los sindicatos y a las organizaciones políticas situadas a su izquierda que luchaban contra sus planes, de fusionarse con la derecha para desgastar al partido socialista. De ahí que, quizás, la contestación debería haber hecho hincapié en denunciar, fundamentalmente, a los responsables directos de la crítica situación, al objeto de facilitar una diferenciación en las críticas vertidas contra las reformas que se pretendían llevar a cabo en el aparato industrial español.

Era vital comprender que, en aquellas circunstancias, la clase trabajadora y otras capas sociales desfavorecidas de manera mayoritaria, así como sectores amplios de las clases medias, no querían cambiar de gobierno - lo acababan de elegir masivamente-, a diferencia de lo que sí pretendía la derecha. Se trataba, en todo caso, de convencer a una parte de los votantes socialistas de que la política que propugnaban los líderes del PSOE no era el camino que debía recorrer un partido de izquierdas «apellidado socialista y obrero».

Por otro lado, eso debía traducirse en que, para lograr dicho cambio, la unificación con el resto de sectores en lucha era una condición sine qua non. Por muchas movilizaciones que realizaran los trabajadores de Sagunto, y por muy radicalizadas que fueran, era prácticamente imposible que ellos solos modificasen los planes del Gobierno. Con dicha unificación, posiblemente, se habrían agudizado las fricciones ya existentes entre los ministros socialistas y en el seno del propio partido como consecuencia de la fuerte contestación social derivada de la aplicación de sus políticas.

En el ámbito organizativo, la CS se apoyaba en las asambleas del pueblo, en donde se decidían los pasos a dar. Las diversas formas de organización colectiva se fueron expresando entre las mujeres, los jóvenes, los estudiantes, en unos casos de manera espontánea y en otros impulsados por las organizaciones de clase, 
siendo su vehículo de expresión la asamblea. Sin embargo, estos colectivos que participaban denodadamente por salvar los puestos de trabajo carecían de representación, surgiendo tensiones y roces que provocaron, en varios momentos claves del conflicto, efectos negativos en la propia lucha.

A estas insuficiencias, se añadían las tensas y contradictorias relaciones entre miembros del CE y entre éste y la CS. En la medida que la lucha trascendía los límites de AHM y sin renunciar a que el órgano de representación de la plantilla siguiera siendo dicho CE, la CS podría haber incluido, también, a los representantes del Comité, sometiéndose a las decisiones que se tomaran democráticamente en la asamblea del pueblo. Este mecanismo de organización de la lucha hubiera podido generalizarse al conjunto de las zonas afectadas, máxime cuando los sindicatos de clase y los partidos de izquierda —había organizaciones del PSOE que participaban en las movilizaciones- estaban liderando el proceso en todo el Estado.

Sería, por tanto, muy conveniente profundizar como línea futura de investigación hasta qué punto hubo una vinculación -y si la hubo, descubrir qué grado de relación tuvo- entre el programa y la táctica con que abordaron la lucha las direcciones de CCOO y UGT, junto al PCE, y el resultado obtenido en la misma. También, nos podría indicar si la determinación mostrada por la plantilla y el resto del pueblo saguntino requería un programa y una táctica diferente a la empleada para conseguir derrotar los planes gubernamentales o, si por el contrario, éstos gozaban de un sustento social tan amplio que hacía inviable cualquier tipo de lucha que se emprendiera.

En este sentido, quizás sería conveniente hacerse eco de las palabras de uno de los líderes de la Revolución Francesa, Maximilien de Robespierre, cuando, en sus Lettres á ses commettants (Oeuvres, tercer volumen) afirmaba, en relación al desenlace de los conflictos bélicos, que «el éxito o el fin de la guerra depende menos de la grandeza de los preparativos y del número de soldados que del espíritu del gobierno y de los principios». 